Cite this: Chem. Commun., 2014 , 50, 7477

Received 17th February 2014, Accepted 27th May 2014

DOI: $10.1039 / \mathrm{c} 4 \mathrm{cc} 01250 \mathrm{j}$

www.rsc.org/chemcomm

\section{Neocuproine-functionalized silica-coated magnetic nanoparticles for extraction of copper(II) from aqueous solution $\$$ \$}

\author{
Ashfaq Afsar, ${ }^{a}$ Laurence M. Harwood, ${ }^{* a}$ Michael J. Hudson, $^{a}$ Mark E. Hodson ${ }^{b}$ and \\ Elizabeth J. Shaw ${ }^{c}$
}

\begin{abstract}
Neocuproine has been covalently bound to silica-coated maghemite $\left(\gamma-\mathrm{Fe}_{2} \mathrm{O}_{3}\right)$ magnetic nanoparticles (MNPs) by a phenyl ether linkage. The resulting MNPs are able to remove $\mathrm{Cu}(\mathrm{\prime \prime})$ from $12 \mathrm{ppm}$ aqueous solution with an extraction efficiency of up to $99 \%$ at $\mathrm{pH} 2$.
\end{abstract}

Magnetic nanoparticles (MNPs) combine high surface area with ease of separation ${ }^{1}$ and the use of iron oxide particles has opened fascinating separation applications. ${ }^{2-7}$ However, iron oxide based MNPs in combination with complexing agents cannot be used in acidic media, which would dissolve the particles. ${ }^{8}$ A way to solve this problem is to use silica to provide a chemically unreactive surface whilst not affecting the core. ${ }^{8}$ Furthermore, the free $\mathrm{Si}-\mathrm{OH}$ surface groups can allow effective covalent binding of organic functional groups onto the surface of the $\mathrm{SiO}_{2}$-coated MNPs. Commonly, surface modification with alkoxysilanes of the general formula $\mathrm{X}-\left(\mathrm{CH}_{2}\right)_{n}-\mathrm{Si}(\mathrm{OR})_{3}$, is used where $\mathrm{X}$ represents the head-group functionality, $\left(\mathrm{CH}_{2}\right)_{n}$ that acts as a flexible spacer, and $\mathrm{Si}(\mathrm{OR})_{3}$ the anchor group that can attach to the free $\mathrm{Si}-\mathrm{OH}$ groups on the surface of the MNPs. ${ }^{9,10}$ The present work combines the stability of $\mathrm{SiO}_{2}$-coated MNPs and the complexing power of neocuproine ${ }^{11}$ in order to study the capabilities of such materials for the effective removal of $\mathrm{Cu}$ (II) from aqueous solutions at different $\mathrm{pH}$.

Iron oxide $\left(\gamma-\mathrm{Fe}_{2} \mathrm{O}_{3}\right)$ MNPs were prepared by co-precipitation ${ }^{8,12-14}$ from a $1: 2$ aqueous mixture of $\mathrm{FeCl}_{2}$ and $\mathrm{FeCl}_{3}$ with sodium hydroxide. The external silica layer was then coated onto the surface of the MNPs by a sol-gel method using tetraethyl orthosilicate (TEOS). ${ }^{8,12-14}$ After this, the silica surface was further modified with 3-iodopropyltrimethoxysilane (3-IPTMS) (Scheme 1).

\footnotetext{
${ }^{a}$ School of Chemistry, University of Reading, Whiteknights, Reading, Berkshire RG6 6AD, UK. E-mail: l.m.harwood@reading.ac.uk

${ }^{b}$ Environment Department, University of York, Heslington, York, YO10 5DD, UK ${ }^{c}$ Department of Geography and Environmental Science, University of Reading, Whiteknights, Reading, Berkshire RG6 6AD, UK

$\dagger$ Dedicated to Richard Taylor, a colleague and valued friend, to celebrate his 65 th birthday.

\$ Electronic supplementary information (ESI) available: Experimental details and characterization of compounds. See DOI: $10.1039 / \mathrm{c} 4 \mathrm{cc} 01250 \mathrm{j}$
}

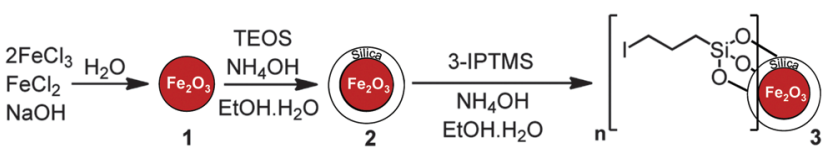

Scheme 1 Synthesis of iodoalkyl-functionalized $\mathrm{SiO}_{2}$-coated MNPs 3.

In order to introduce functionality at the 5-position of neocuproine 4 , bromination ${ }^{15,16}$ was carried out with bromine (0.6 equivalents) in the presence of fuming $\mathrm{H}_{2} \mathrm{SO}_{4}\left(20 \% \mathrm{SO}_{3}\right)$. Replacement of the bromine with a 4-hydroxyphenol linking group was successfully achieved via Suzuki coupling ${ }^{17}$ with 4-hydroxyphenylboronic acid (Scheme 2). This phenol functionalized ligand could then be immobilized onto the MNPs by nucleophilic substitution of the iodo-substituent (Scheme 3).

Each functionalization step of the MNPs was followed by infrared spectroscopy. Fig. 1 depicts the FT-IR spectra of uncoated $\left(\gamma-\mathrm{Fe}_{2} \mathrm{O}_{3}\right)$ MNPs $1, \mathrm{SiO}_{2}$-coated MNPs 2 and iodoalkylfunctionalized $\mathrm{SiO}_{2}$-coated MNPs 3. The $\gamma-\mathrm{Fe}_{2} \mathrm{O}_{3}$ MNPs 1 cause

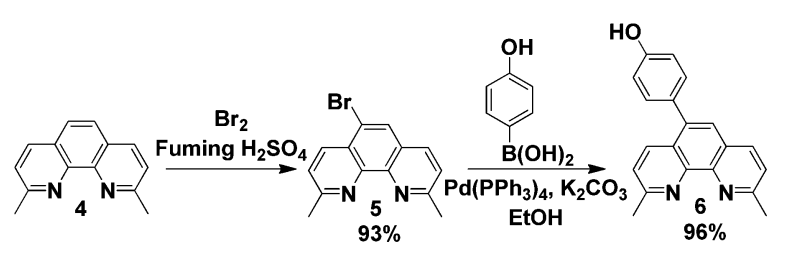

Scheme 2 Synthesis of 5-(4-hydroxyphenyl)-2,6-dimethyl-1,10-phenanthroline 6.

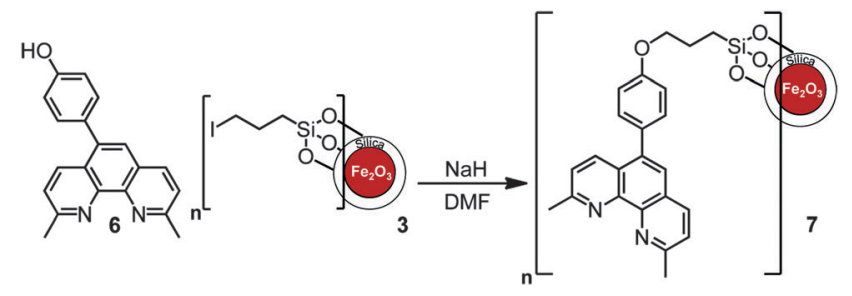

Scheme 3 Immobilisation of neocuproine on MNPs. 


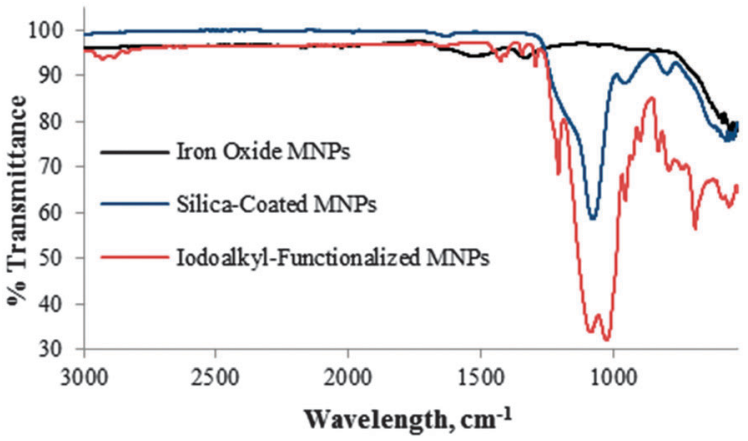

Fig. 1 FR-IR spectra of $\mathrm{Fe}_{2} \mathrm{O}_{3}$ 1, $\mathrm{SiO}_{2}$-coated $\mathrm{Fe}_{2} \mathrm{O}_{3}$ 2, and iodoalkylfunctionalized $\mathrm{SiO}_{2}$-coated MNPs 3 .

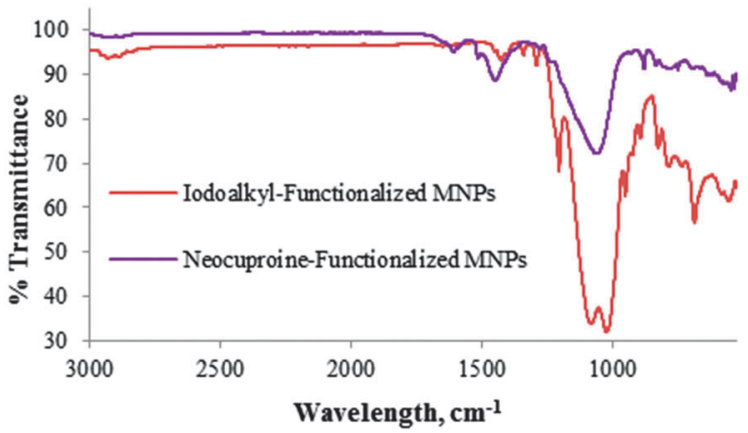

Fig. 2 FR-IR spectra of iodoalkyl-functionalized $\mathrm{SiO}_{2}$-coated MNPs 3 and neocuproine-functionalized $\mathrm{SiO}_{2}$ coated MNPs 7.

two strong absorptions at 630 and $580 \mathrm{~cm}^{-1}$. The introduction of silica on the surface of the $\gamma-\mathrm{Fe}_{2} \mathrm{O}_{3}$ MNPs 1 results in an additional absorption band at $1080 \mathrm{~cm}^{-1}$ owing to $\mathrm{Si}-\mathrm{O}$ stretching. After functionalization with 3-iodopropyltrimethoxysilane, bands at $2930 \mathrm{~cm}^{-1}$ and $688 \mathrm{~cm}^{-1}$ were observed, assigned to the $\mathrm{C}-\mathrm{H}$ stretching and C-I stretching modes of iodoalkyl-functionalized $\mathrm{SiO}_{2}$-coated MNPs 3 , respectively.

The FT-IR spectra shown in Fig. 2 demonstrate a clear distinction between iodoalkyl-functionalized $\mathrm{SiO}_{2}$-coated MNPs 3 and neocuproine-functionalized $\mathrm{SiO}_{2}$-coated MNPs 7. Absence of the C-I stretching absorption at $688 \mathrm{~cm}^{-1}$ and presence of bands at $1500-1600 \mathrm{~cm}^{-1}$ owing to $\mathrm{C}=\mathrm{C}$ aromatic vibrations are indicative of the covalent incorporation of neocuproine onto the MNPs.

The unfunctionalized $\gamma-\mathrm{Fe}_{2} \mathrm{O}_{3}$ MNPs 1 were characterized by $\mathrm{X}$-ray powder diffraction ${ }^{18}$ and were found to consist of pure maghemite or $\gamma-\mathrm{Fe}_{2} \mathrm{O}_{3} ;{ }^{19}$ whereas diffraction data of the composite nanoparticles after modification with silica did not show any well defined peaks (ESI ), indicating that the silica coating is thick enough to interfere with the iron oxide diffraction, or the iron oxide is more amorphous than before (smaller particles, smaller diffracting domains or more disordered structure) allowing the silica pattern to dominate.

Representative TEM images of $\gamma-\mathrm{Fe}_{2} \mathrm{O}_{3}$ MNPs 1, iodoalkylfunctionalized $\mathrm{SiO}_{2}$-coated MNPs 3 and neocuproinefunctionalized $\mathrm{SiO}_{2}$-coated MNPs 7, shown in Fig. 3, were recorded on the particles dispersed in methanol and dried on a copper grid at room temperature.

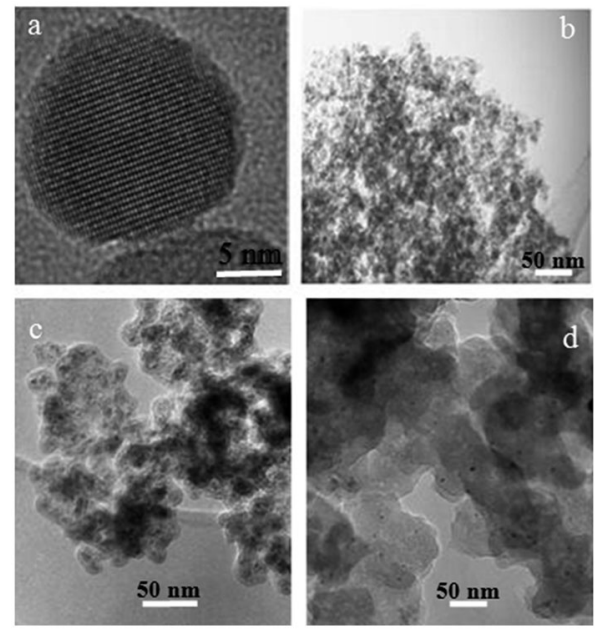

Fig. 3 TEM images of $(a, b) \gamma-\mathrm{Fe}_{2} \mathrm{O}_{3}$ MNPs 1, (c) iodoalkyl-functionalized $\mathrm{SiO}_{2}$-coated MNPs 3 and (d) neocuproine functionalized MNPs 7.

Fig. 3(a) shows the predominantly spherical morphology of the $\gamma-\mathrm{Fe}_{2} \mathrm{O}_{3}$ MNPs 1 with an average diameter of $c a .15 \mathrm{~nm}$. These tended to form aggregates as shown in Fig. 3(b). In the case of iodoalkyl-functionalized $\mathrm{SiO}_{2}$-coated MNPs 3 [Fig. 3(c)], the diameter of the particles was found to be $c a .20-25 \mathrm{~nm}$, while Fig. 3(d) reveals that neocuproine-functionalized $\mathrm{SiO}_{2}$ coated MNPs 7 have diameter of $c a .50-55 \mathrm{~nm}$.

To complement the TEM images that only provide information on the size of the MNP cores, DLS measurements (ESI $\ddagger$ ) were also carried out. This indicated the $\gamma-\mathrm{Fe}_{2} \mathrm{O}_{3}$ MNPs 1, iodoalkylfunctionalized $\mathrm{SiO}_{2}$-coated MNPs 3 and neocuproine-functionalized $\mathrm{SiO}_{2}$-coated MNPs 7 to have narrow particle size distributions and average diameter values of 15,48 , and $72 \mathrm{~nm}$, respectively. The values measured for the iodoalkyl-functionalized $\mathrm{SiO}_{2}$-coated MNPs 3 and neocuproine-functionalized $\mathrm{SiO}_{2}$-coated MNPs 7 are larger compared to the TEM images; this phenomenon has been observed previously. ${ }^{20,21}$

The organic content on the MNPs was investigated using thermal gravimetric analysis (TGA) under nitrogen. The weight loss for the $\mathrm{SiO}_{2}$-coated MNPs 2 was about $2.5 \%$ over the temperature range from $60-200{ }^{\circ} \mathrm{C}$, presumably due to the loss of residual water; whereas the TGA curve of iodoalkylfunctionalized $\mathrm{SiO}_{2}$-coated MNPs 3 showed a sharp weight loss

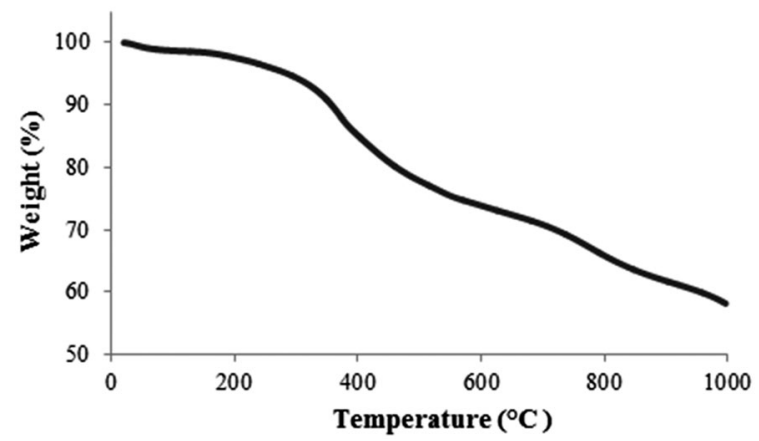

Fig. 4 TGA curve of MNPs 7. 
at $250-300{ }^{\circ} \mathrm{C}$, proposed to correspond to the loss of iodoalkyl coating (ESI ). The TGA curve (Fig. 4) of neocuproinefunctionalized $\mathrm{SiO}_{2}$-coated MNPs 7 shows three weight-loss steps. Below $200{ }^{\circ} \mathrm{C}$, the weight loss is quite small, probably resulting from the removal of absorbed water. After that, there is a significant weight loss from $300-500{ }^{\circ} \mathrm{C}$ corresponding to the decomposition of the organic components. From this, it can be estimated that the amount of neocuproine bound onto the MNPs is about $\sim 15 \% \mathrm{w} / \mathrm{w}$ (ESI ). Further weight loss at 700 $900{ }^{\circ} \mathrm{C}$ can be attributed to the formation of iron carbide. ${ }^{22,23}$

The extraction of $\mathrm{Cu}(\mathrm{II})$ from aqueous media was tested by weighing about $12 \mathrm{mg}$ of functionalized MNPs 7 into plastic tubes containing $10 \mathrm{~mL}$ solutions of $12 \mathrm{ppm}$ of $\mathrm{Cu}(\mathrm{II})$ at different $\mathrm{pH}$. The mixtures were sonicated for $5 \mathrm{~min}$ and then shaken overnight. A neodymium permanent magnet was placed for 60 seconds beneath the tube to move the MNPs to the tube wall allowing the supernatant liquid to be decanted. After separation, the supernatant was subjected to quantitative elemental analysis by atomic absorption spectrometry.

Acidity of an aqueous solution is known to exert a profound influence on extraction efficiency of various ligands. ${ }^{5}$ The effect of solution $\mathrm{pH}$ on $\mathrm{Cu}$ (II) extraction was investigated in the range $\mathrm{pH}$ 2-8. As shown in Fig. 5, close to 99\% of $\mathrm{Cu}$ (II) was removed at $\mathrm{pH} 2$ (initial concentration $12.33 \mathrm{ppm}$, final concentration $0.13 \mathrm{ppm}$ ); although the extraction efficiency decreased with increasing the $\mathrm{pH}$. The lowest $\mathrm{pH}$ was then selected for kinetic studies where extraction was effectively complete after 5 min (ESI ).

The percentage of $\mathrm{Cu}$ (II) extraction from a $12 \mathrm{ppm}$ initial concentration with different amounts of neocuproinefunctionalized MNPs 7 at pH 2 is presented in Fig. 6 and shows

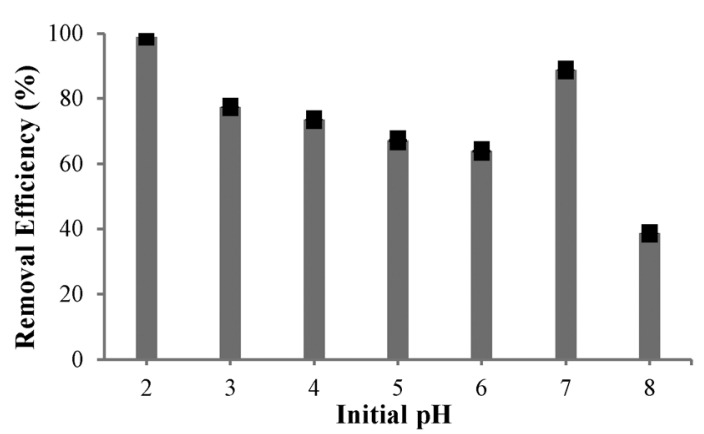

Fig. 5 Effect of initial $\mathrm{pH}$ on the extraction efficiency of $\mathrm{Cu}($ (I) by MNPs 7.

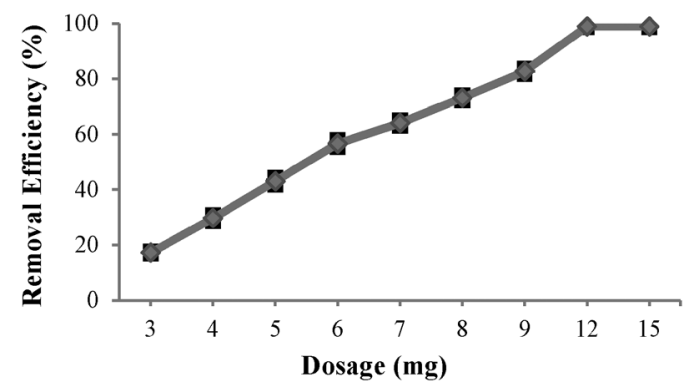

Fig. 6 Effect of MNPs 7 dosage on extraction of $\mathrm{Cu}(॥)$.
Table 1 Extraction of $\mathrm{Cu}(\mathrm{II})$ from aqueous solution at $\mathrm{pH} 2$ by $\mathrm{SiO}_{2}$-coated $\mathrm{Fe}_{2} \mathrm{O}_{3}$ 2, iodoalkyl-functionalized $\mathrm{SiO}_{2}$-coated MNPs 3 and neocuproine functionalized MNPs 7

Removal (\%)

\begin{tabular}{lll}
\hline $\mathrm{SiO}_{2}$-coated MNPs & $\begin{array}{l}\text { Iodoalkyl-functionalized } \\
\mathrm{SiO}_{2} \text {-coated MNPs }\end{array}$ & $\begin{array}{l}\text { Neocuproine } \\
\text { functionalized MNPs }\end{array}$ \\
\hline 17 & 30 & 99
\end{tabular}

an almost linear correlation of $\mathrm{Cu}(\mathrm{II})$ extraction with the amount of MNPs 7 added.

To assess the chelating effect of the bound neocuproine in functionalized MNPs 7, the extraction efficiencies of $\mathrm{SiO}_{2}$-coated $\mathrm{Fe}_{2} \mathrm{O}_{3}$ MNPs 2 and iodoalkyl-functionalized $\mathrm{SiO}_{2}$-coated MNPs 3 were also investigated at $\mathrm{pH} 2$ and compared with the extraction efficiency of neocuproine functionalized MNPs 7 (Table 1).

The extraction efficiencies of $\mathrm{SiO}_{2}$-coated $\mathrm{Fe}_{2} \mathrm{O}_{3}$ MNPs 2 and iodoalkyl-functionalized $\mathrm{SiO}_{2}$-coated MNPs 3 were found to be $17 \%$ and $30 \%$, respectively; compared to the $99 \%$ extraction efficiency observed for neocuproine functionalized MNPs 7 . Thus, the majority of the extraction capacity of functionalized MNPs 7 is due to the bound neocuproine.

In summary, neocuproine functionalized MNPs 7 have been prepared and characterised. These MNPs have the advantages of high surface area and their ability to be separated from aqueous media magnetically. Their ability to extract $\mathrm{Cu}$ (II) from aqueous media has been investigated at varying $\mathrm{pH}$, with the maximum extraction efficiency of $\mathrm{Cu}$ (II) by the MNPs being found to be $99 \%$ at pH 2. Extraction was complete within $5 \mathrm{~min}$ and about $12 \mathrm{mg}$ of these MNPs were able to alter the concentration of $\mathrm{Cu}$ (II) in $10 \mathrm{~mL}$ of solution from $12.33 \mathrm{ppm}$ to $0.13 \mathrm{ppm}$.

The authors acknowledge the EPSRC for financial support (A.A.). Use of the Chemical Analysis Facility (CAF) and Centre for Advanced Microscopy (CfAM) at the University of Reading is gratefully acknowledged. We also would like to thank $\mathrm{Mr}$ Michael Andrews, Dr Peter Harris and Miss Anne Dudley for their assistance with X-ray diffraction (XRD), Transmission Electron Microscopy (TEM) and Atomic Absorption (AA) measurements, respectively.

\section{Notes and references}

1 A.-F. Ngomsik, A. Bee, D. Talbot and G. Cote, Sep. Purif. Technol., 2012, 86, 1-8.

2 Y. Sun, X. Ding, Z. Zheng, X. Cheng, X. Hu and Y. Peng, Chem. Commun., 2006, 2765-2767.

3 F. M. Koehler, M. Rossier, M. Waelle, E. K. Athanassiou, L. K. Limbach, R. N. Grass, D. Gunther and W. J. Stark, Chem. Commun., 2009, 4862-4864.

4 X. Liu, Q. Hu, Z. Fang, X. Zhang and B. Zhang, Langmuir, 2009, 25, 3-8.

5 Y. Liu, M. Chen and H. Yongmei, Chem. Eng. J., 2013, 218, 46-54.

6 M. Kaur, A. Johnson, G. Tian, W. Jiang, L. Rao, A. Paszczynski and Y. Qiang, Nano Energy, 2013, 2, 124-132.

7 M. H. Mashhadizadeh and Z. Karami, J. Hazard. Mater., 2011, 190, 1023-1029.

8 J. H. Jang and H. B. Lim, Microchem. J., 2010, 94, 148-158.

9 I. J. Bruce and T. Sen, Langmuir, 2005, 21, 7029-7035.

10 M. Yamaura, R. L. Camilo, L. C. Sampaio, M. A. Macêdo, M. Nakamura and H. E. Toma, J. Magn. Magn. Mater., 2004, 279, 210-217. 
11 P. Ashtari, K. Wang, X. Yang and S. J. Ahmadi, Anal. Chim. Acta, 2009, 646, 123-127.

12 A. L. Morel, S. I. Nikitenko, K. Gionnet, A. Wattiaux, J. Lai-Kee-Him, C. Labrugere, B. Chevalier, G. Deleris, C. Petibois, A. Brisson and M. Simonoff, ACS Nano, 2008, 2, 847-856.

13 M. Nazrul Islam, L. Van Phong, J.-R. Jeong and C. Kim, Thin Solid Films, 2011, 519, 8277-8279.

14 F. W. Zhang, Z. Z. Zhu, Z. P. Dong, Z. K. Cui, H. B. Wang, W. Q. Hu, P. Zhao, P. Wang, S. Y. Wei, R. Li and J. T. Ma, Microchem. J., 2011, 98, 328-333.

15 J. Mlochowski, Rocz. Chem., 1974, 48, 2145-2155.

16 A. Afsar, D. M. Laventine, L. M. Harwood, M. J. Hudson and A. Geist, Chem. Commun., 2013, 49, 8534-8536.
17 J. P. W. Eggert, U. Luning and C. Nather, Eur. J. Org. Chem., 2005, 1107-1112.

18 A. Afsar, D. M. Laventine, L. M. Harwood, M. J. Hudson and A. Geist, Heterocycles, 2014, 88, 613-620.

19 T. Hyeon, S. S. Lee, J. Park, Y. Chung and H. B. Na, J. Am. Chem. Soc., 2001, 123, 12798-12801.

20 L. Sun, C. Huang, T. Gong and S. Zhou, Mater. Sci. Eng., C, 2010, 30, 583-589.

21 J. Lim, S. Yeap, H. Che and S. Low, Nanoscale Res. Lett., 2013, 8, 381. 22 R. Snovski, J. Grinblat, M.-T. Sougrati, J.-C. Jumas and S. Margel, J. Magn. Magn. Mater., 2014, 349, 35-44.

23 M. Sharma, S. Mantri and D. Bahadur, J. Magn. Magn. Mater., 2012, 324, 3975-3980. 